as a detonating agent, a few words may be said upon the report of the Chief Inspector of Explosives that has just been issued by the Home Office. If only because it controverts a popular notion as to the dangers of this substance in a frozen state, the report in question is of considerable interest. Ever since the disastrous accident at Newcastle-upon-Tyne, when Mr. Mawson, the mayor of the city and several others lost their lives through the explosion of some packages supposed to have contained frozen nitro-glycerine, a wholesome dread of this substance has been entertained. But, strange to say, Major Majendie and Mr. E. O. Brown, of Woolwich, who appears to have been associated with the Chief Inspector in these experiments with frozen nitro-glycerine, found the latter far less sensitive either to blows or to fulminate powder than when in its ordinary condition. In some cases the frozen material allowed itself to be scattered by the violence used, without detonating at all, and it was only by using a very large charge of fulminate powder that its explosion succeeded. Frozen dynamite was still more obstinate, and under some circumstances, indeed, its detonation appeared almost impossible. Another circumstance of an unexpected character presented itself in these experiments. Mr. Brown found that the solidification of nitro-glycerine-a phenomenon that usually happens very readily some degrees above the freezing-point of water-is particularly difficult to bring about when the liquid is in a pure state. Continued subjection of the pure liquid to a temperature below freezing-point failed altogether to effect its solidification, and it was only upon the addition of a few grains of a solid body that the desired result was secured. The reason, therefore, why commercial nitro-glycerine so readily solidifies at a comparatively high temperature is obviously because it is not perfectly pure.

H. BADEN PRITCHARD

\section{THE BRITISH MUSEUM LIBRARY}

N NATURE, vol. xix. p. 253 , attention was drawn to the state of the literature of science as available for reference in the library of the British Museum. The publications of scientific societies, home, colonial, and foreign, and those of the scientific departments of different governments, were especially mentioned both as defective in regard to completeness of series, and as difficult to find in the catalogue.

Pending steps being taken to secure some approximasion to completeness of series, which must take time, it may be useful to offer some suggestions with regard to the cataloguing, a modification in which would save much time to readers. Any fundamental alteration would no doubt be undesirable, for from a librarian's point of view, the cataloguing at the British Museum has been so often pronounced excellent. There is, however, also the worker's point of view, and if the catalogue is not one which, after years of experience he can easily use, it is not to be accounted as perfect.

The simplest solution of the present difficulty would be to have printed a separate list, such as the Patent Office periodically prints, "a list of the scientific and other periodicals and transactions of learned societies in the free library." Should there be, however, a financial difficulty in the way of carrying this out, it would be a saving of time to readers if these transactions, proceedings, \&c., of societies were entered in some distinctive way, such as by a coloured ink, or even by a stroke in the margin, so that they might be easily picked out from bye-laws, lists of members, reprints of separate papers, \&c. Several of the older societies occupy many pages in the special catalogue "academies." It is the publication of the societies containing the papers that are, of course, most frequently wanted, but these are so mixed up with other entries, that it takes time to find their press mark. Further than that, different series, when such exist, have different press marks, and it is not every one who has a date and a volume number for reference that knows whether there is more than one series, so a wrong pressmark may be given. In some cases there are two or three sets, more or less incomplete, of a series of publications, some, perhaps, in the King's library, some in the Granville, some in the general library, \&c. This is very confusing, as it is only in a few cases that any note is made of the extent of incompleteness, and if the wrong set should be written for, it involves the loss of at least half an hour, and on busy days probably an hour.

If all the serial publications of a society were given at the head of the entries of that society, or even if only marked in the margin as just suggested, it would save a reader much time in finding the press mark, and would also save still further time often by giving the press mark for the part of the series which contains the volume wanted.

There is another point which is worth consideration, and that is whether those who are known to use the library for purposes of research could not be in some way put on a different footing from those who go simply to read. It would not be an innovation, but only an extension of a principle already recognised. For example, if a reader wishes to consult certain MSS., he is taken into a separate room, if he wishes to consult some of the older or rarer books, there is another room for such purpose, and there is but little time wasted in bringing him what he wants. Students are admitted to the natural history collections on days when they are closed to the public. There are a large number of people who use the museum for other purposes than work. They write their letters, read their magazines and newspapers, go round among their friends and gossip, write a ticket for some interesting book of travel or a novel, and read bits of it in the interval of receiving visits. Not a few appear to go there for a rest. The objection to all this is that these people occupy seats, and it is becoming more and more difficult for a reader with many books out at once for consultation or search to find table space. It is a very trying thing for a writer with references to verify or to follow up, to see while he is waiting for his books that the time of attendants is occupied in fetching novels that can be bought at any railway book-stall, or pieces of music that can be obtained for a few pence. (It may be mentioned in passing that for the cataloguing of comic songs and dance music, the British Museum is unsurpassed in excellence.) It must require a strong sense of the immorality of making quotations or references second-hand, to give a man patience under the circumstances. If the works are wanted for reading there is of course no help but waiting.

Surely there might be some distinction made between those who go to the reading-room for systematic work, and those who go for amusement. The British Museum reading-room is something more than a library for Londoners; people come up to town on purpose to consult it. It is a national library. An average mechanics' Institute would supply the wants of many who now use the Museum, occupy seats there, and take up the time of attendants. There are other free libraries in London besides the British Museum.

If it is not found practicable to make a distinction for workers generally it might be worth while to try how it would do to have tickets of a special colour for "Academies" and that these should not be obliged to wait their turn with tickets for novels. There are already white and coloured slips in use.

It would be a great advantage if the publications of societies and scientific departments of governments were kept all together and placed directly under the care of an offieer who should see to their being kept up in completeness.

\section{ON THE FIGURE OF THE EARTH}

THE columns of NATURE recently contained an interesting series of articles on this subject, with notes. One of these notes, which I here repeat, has_a 
peculiar interest. The author says: "The theory was next propounded that the earth was an ellipsoid of three axes, but the proposition was not fully supported by the evidence." Upon this Col. Clarke remarks: "This is scarcely correct ; the figure of three unequal axes agrees better with the observations than does the spheroid of revolution. But there is a necessity for this, and the ellipsoidal figure cannot be regarded as established."

I venture to think that this note ought to be printed in capital letters. It condenses, especially in the words, "but there is a necessity for this," the following important paragraph in the preamble to Col. Clarke's wellknown paper in the Memoirs of the Royal Astronomical Society, 1861 :-

"Whatever the real figure of the earth may be, if in the investigation we suppose it an ellipsoid, it is quite clear that the arithmetical process must bring it out an ellipsoid of some kind or other, which ellipsoid will agree better with all the observed latitudes, as a whole, than any spheroid of revolution will. Nevertheless it would scarcely, I conceive, be correct to say we had proved the earth not to be a solid of revolution. To prove this would require data which we are not in possession of at present, which must include several arcs of longitude. In the meantime it is interesting to ascertain what ellipsoid does actually best represent the existing measurements."

It may seem superfluous, so far as the main point is concerned, to add anything to these quotations : but of the three which have been given, I have very little doubt that the first was by way of a protest against the fallacy which, in spite of the last, has gained such a remarkable currency. An I mistaken in thinking that it is a tooprevalent opinion that the equatorial section has been shown to be elliptical? It may be so ; but I conceive it to be so noxious an error, when it does exist, that it is better to give too much than too little currency to every authoritative corrective of such an error.

It is very much to be regretted when investigations which are essentially tentative, and which are carefully guarded as such by sentences which are to be found if looked for, obtain through no fault of their own the character of demonstrations. I think Col. Clarke has run the risk of giving to the above fallacy a stronger hold by neglecting to emphasise with sufficient force, in his more recent calculations, their true character; and perhaps still more by seeming to entertain something of an expectation that the arithmetical result will be substantiated by increased data. Writing of the later result -as to which we may properly note that the equatorial major axis occupies a position differing from that of the former by $24^{\circ}$ of longitude-he says: "But too much confidence must not be placed in it : as yet it is merely indicated by the existing observations, and the amount of the eccentricity of the equator shown is really very minute."

I am unwilling to seem to differ from so high an authority, especially on a point which I wish to have "reserved:" I therefore refrain from inquiring whether any such expectation is really entertained, preferring to adduce some arguments which tell the other way.

Whatever the real figure of the earth may be, it is as certain that, if we knew it exactly in every part-instead of only very uncertainly in a very few-a triaxial ellipsoid could be found which would fit it better than any other triaxial ellipsoid, as it is that a biaxial ellipsoid could be found which would fit a given egg better than any other biaxial ellipsoid. But we happen to know that eggs are generally egg-shaped, and not elliptical. So also we know-I hope it is not necessary to stop to prove this-that the earth is earth-shaped, and not ellipsoidal If the best possible ellipsoid were fitted to it, the two would disagree everywhere more or less. It is not, therefore, as regards the present argument, a question of more data. If the figure were conformable to any ellipsoid, the existing data would suffice. Their insufficiency proves the non-conformity, and additional data cannot disprove it.

What additional data may be expected to do is to modify the approximate ellipsoid until the ellipticity of its equator disappears-in other words, until it becomes an elliptic spheroid.

Can I give any ground for this expectation? It would be fair to ask in return, Can any ground be shown for expecting a body, believed to have acquired its spheroidal form by rotation,' to have an equator not circular? I will answer the latter inquiry first, myself. The same, or similar, causes which distributed land and sea irregularly have probably produced an equator which is not circular. But I know nothing to lead me to expect that the form of the equator has any better claim to be considered elliptical than circular, than this-an ellipse can generally be found which will fit an irregular area better than a circle. This argument can be turned against me, but only by admitting the irregularity. If the irregularity is admitted, I concede an elliptic equator for the approximate or mean figure. And the question is now reduced to one of degree.

The difference of equatorial semi-axes in Clarke's earlier investigations was 5,308 feet (186I), and subsequently 6,378 (I866). It is now 1,524 feet.

We are here, to go no further, within the limit of inequality assignable to the larger disturbances of sealevel; that is to say, to one kind only, of local irregularity.

In short, while I recognise with the most unreserved respect and admiration the labours which have resulted from the first attempt to ascertain whether a tri-axial ellipsoid was sufficiently indicated to be : robable, I presume to think that Colonel Clarke's words of caution demand the utmost attention, and that the results at which he has? arrived should be construed rather as disproving than as proving the reality of a sensibly elliptic equator.

I should extend this article too far if I did more than indicate one other ground for caution in describing the figure of the earth. Our knowledge on that head, as derived from arc-measures, is deceptive in proportion as we lose sight of the significance of the fundamental assumption that the figure is a regular one. Gross assumptions which suit an early stage of an inquiry may have to be abandoned later. The forms of the surfaces whose curvatures arc-measurements determine, are in any case local and particular; and so soon as local character appears, further consideration of the assumption is demanded. This, no doubt, is the reasoning out of which the tri-axial ellipsoid grew. It must not stop there. The tri-axial ellipsoid is not the only next step. Forced by the rigour of observation to abandon the ellip. tic spheroid as a final definition, and to admit irregularities as coming now within the range of more particular inquiry, the prob!em has in effect changed its face. To cling to the old assumption is to delay the recognition of the new phase. To look for additional data as means of substantiating or modifying an empirical modification of it is to halt in the presence of the larger problem which is opening before us.

Will it not be wiser to change the mode of attack? To bestow increased attention on the causes of irregularities and the probable magnitude of their effects? To theorise and calculate in this direction, on the one hand, and to extend experiment on the other, where such reasoning shall point the way? If we do this, the ultimate inadequacy of arc-measurements must receive recognition. The most obvious of all the causes of irregularity-the fluidity of the ocean and its obedience to the attraction of the land masses, must, one would think, invalidate their evidence materially. If, further, we consider the 
actual conformations of the great terrestrial divisions of land and sea, arcs of longitude are, I imagine, especially likely to be affected by such causes.

The views which I have now attempted to express are by no means new, but it has not appeared necessary to cite authorities. I am indebted to many writers, but I should be sorry to have to assign to each the measure of the influence which his learning has had on the drawing up of this brief, which I hope some geodesist will now take up and argue more fully and more ably.

$$
\text { Dehra }
$$

J. Herschel

\section{THE ROYAL SOCIETY SOIREE}

$\mathrm{O}^{\mathrm{N}}$ Wednesday last week the President of the Royal Society gave a soirée at Burlington House, which was largely attended, and at which a considerable variety of apparatus were exhibited and many experiments made. Mr. Crookes showed his exhausted tubes and other apparatus, illustrating various phenomena connected with molecular physics in high vacua. The experiments made by these were the following:-

1. Dark Space round the Negative Pole.-When the spark from an induction coil is passed through an ordinary vacuum tube, a dark space is seen round the negative pole. The shape and size of this dark space do not vary with the distance separating the poles; nor, only very slightly, with alteration of battery power, or with intensity of spark. This well-known dark space appears to be a layer of molecular disturbance identical with the invisible layer of molecular pressure o: stress, the invescigation of which has occupied the exhibitor some years.

2. The Electrical Radiometer.-An ordinary radiometer is furnished with aluminium cups for vanes. The fly is supported by a hard steel cup, and the needle point on which it works is connected with a platinum terminal sealed into the glass. At the top of the radiometer bulb a second terminal is sealed in ; the radiometer can therefore be connected with an induction coil, the movable fly being made the negative pole. At low exhaustions a velvety violet halo forms over each side of the cup. On increasing the exhaustion the dark space widens out, retaining almost exactly the shape of the cup; the bright margin of the dark space becomes concentrated at the concave side of the cup to a luminous focus, and widens out at the convex side. On further exhaustion, the dark space on the convex side touches the glass, when positive rotation takes place.

3. Green Phosphorescent Light of Molecular Impact.At very high exhaustions the dark space becomes so large that it fills the tube, and when German glass is used the sides are beautifully illuminated with a greenish yellow phosphorescent light.

4. Projection of Molecular Shadows.-The rays exciting this green phosphoresence will not turn a corner in the slightest degree, but radiate from the negative pole in straight lines, casting strong and sharply-defined shadows from objects which happen to be in their path. The best and sharpest shadows are cast by flat disks, and not by narrow pointed poles; no green light is seen in the shadow itself, no matter how thin, or whatever may be the substance from which it is thrown.

5. Magnetic Deflection of the Trajectory of Molecules.The stream of molecules, whose impact on the glass is accompanied by evolution of light, is very sensitive to magnetic influence, and the shadow can be deflected by bringing a small permament magnet near, the amount of deflection of the stream of molecules being in proportion to the magnetic power employed. The trajectory of the molecules forming the shadow is curved when under magnetic influence.

6. Focus of Heat of Molecular Impact.-Great heat is evolved when the concentrated focus of molecular rays from a nearly hemispherical aluminium cup is allowed to fall on a strip of platinum-foil, the heat sometimes exceeding the melting-point of platinum.

7. Mechanical Action of Projected Molecules.-An actual material blow is given by the impinging molecules. A small vaned wheel being used as an indicator, by appropriate means the molecular shadow of an aluminium plate is projected on the vanes. When entirely in the shadow the indicator does not move, but when the molecular stream is deflected so that one-half of the wheel is exposed to molecular impact it rotates with extreme velocity.

8. Phosphorogenic Properties of the Molecular Stream. - Substances known to be phosphorescent under ordinary circumstances shine with great splendour when subjected to the negative discharge in a high vacuum. (a.) Becquerel's Luminous Sulphide of Calcium shines with a bright blue-violet light, and when on a surface of several square inches, is sufficient to faintly light a room. (b.) The Diamond is yery phophorescent. Most diamonds from South Africa phosphoresce with a blue light. Diamonds from other localities shine with different colours, such as bright blue, apricot, pale blue, red, yellowish green, orange, and pale green. One large fluorescent diamond gives almost as much light as a candle when phosphorescing in a good vacuum. (c.) The Ruby glows with a rich full red, and it is of little consequence what degree of colour the stone possesses naturally, the colour of the phosphorescence is nearly the same in all cases.

Besides these experiments the working of the writing telegraph, exhibited by Mr. E. A. Cowper, attracted much interest. The nature of this invention we described when it was first announced, and gave a specimen of the kind of writing produced. Other exhibits deserving notice were Prof. Guthrie's broken glass in frames, illustrating the fracture of colloids, Edison's loud-speaking telephone, Messrs. Preece and Stroh's synthetic curve machine, and frame of curves produced thereby; their automatic phonograph, electromagnetic vowel-sounder, stereoscopic curves, synthetic sounder and syren, and phonautograph. Apparatus and instruments of various kinds were also exhibited by Messrs. Browning, Hilger, and Tisley and Co. Among Mr. Hilger's exhibits was a quartz spectroscope for the ultra-violet rays, constructed for the Scientific Society of Stettin, under the direction of Dr. Schönn.

\section{A NEW CALENDAR CLOCK}

$\mathrm{T} \mathrm{T}$ has always been a matter of surprise that the Americans can produce their well-known eight-day clocks in such large quantities, so uniformly good for ordinary purposes, and at such very moderate cost. Their general efficiency is proved by the increasing demand for them; not only are they sold in the American made cases, but separate movements are extensively imported and cased in England. One of the largest firms by which they are produced, that of Seth Thomas and Co., at Thomaston, Conn., has recently introduced a library or office clock of very moderate cost, one form of which is shown in the accompanying figure. This consists of the ordinary eight-day striking movement supplemented by an interesting and ingenious mechanism for operating the calendar ; by its means not only the month and day of the week and month are indicated as in ordinary calendars, but the several months have their allotted number of days, an additional day being given to February in leapyear. Of course contrivances for effecting this object have long been known, but they always add so materially to the cost that they are prevented from coming into general use.

It would be impossible to fully explain the mechanism employed without the aid of drawings; a general description must therefore suffice. As will be seen, the calendar dial is placed below the clock dial, and is divided on its 